\title{
The genetic diversity and phenotypic characterisation of Streptococcus agalactiae isolates from Rio de Janeiro, Brazil
}

\author{
Ana Beatriz de Almeida Corrêa/ ${ }^{+}$, Lígia Guedes da Silva, Tatiana de Castro Abreu Pinto, \\ Ivi Cristina Menezes de Oliveira, Flávio Gimenis Fernandes, Natalia Silva da Costa, \\ Marcos Corrêa de Mattos, Sergio Eduardo Longo Fracalanzza, Leslie Claude Benchetrit
}

Departamento de Microbiologia Médica, Instituto de Microbiologia Professor Paulo de Góes, Centro de Ciências da Saúde, Universidade Federal do Rio de Janeiro, Av. Carlos Chagas Filho 372, 21941-590 Rio de Janeiro, RJ, Brasil

\begin{abstract}
Streptococcus agalactiae isolates are more common among pregnant women, neonates and nonpregnant adults with underlying diseases compared to other demographic groups. In this study, we evaluate the genetic and phenotypic diversity in $\mathrm{S}$. agalactiae strains from Rio de Janeiro (RJ) that were isolated from asymptomatic carriers. We analysed these S. agalactiae strains using pulsed-field gel electrophoresis (PFGE), serotyping and antimicrobial susceptibility testing, as well as by determining the macrolide resistance phenotype, and detecting the presence of the $\operatorname{erm} A / B, \operatorname{mef} A / E$ and $\operatorname{lnu} B$ genes. The serotypes Ia, II, III and $V$ were the most prevalent serotypes observed. The 60 strains analysed were susceptible to penicillin, vancomycin and levofloxacin. Resistance to clindamycin, chloramphenicol, erythromycin, rifampin and tetracycline was observed. Among the erythromycin and/or clindamycin resistant strains, the $\operatorname{erm} A, \operatorname{erm} B$ and $\operatorname{mef} A / E$ genes were detected and the constitutive macrolides, lincosamides and streptogramin B-type resistance was the most prevalent phenotype observed. The $\ln B$ gene was not detected in any of the strains studied. We found 56 PFGE electrophoretic profiles and only 22 of them were allocated in polymorphism patterns. This work presents data on the genetic diversity and prevalent capsular serotypes among $R J$ isolates. Approximately $85 \%$ of these strains came from pregnant women; therefore, these data may be helpful in developing future prophylaxis and treatment strategies for neonatal syndromes in $R J$.
\end{abstract}

Key words: Streptococcus agalactiae - pulsed-field gel electrophoresis - polymerase chain reaction - antimicrobial susceptibility

The species Streptococcus agalactiae (Group B Streptococcus) is one of the most prevalent causes of human perinatal diseases (Schrag et al. 2000). Pregnant women can be infected with $S$. agalactiae in the vaginal and/or rectal area and this infection can result in septicaemia, corioamniotitis and endometriti. Furthermore, this bacterial infection can also result in miscarriage, stillbirth and newborn death. Among newborns, the microorganism is associated with early onset disease and late-onset disease.

Antibiotics are prescribed to treat infections and prevent early onset disease (CDC 2002). Penicillin is predominantly used in both of these cases. Erythromycin and clindamycin are used in patients who are allergic to beta-lactams when the infections are not resistant to these drugs. Studies conducted in many countries, however, report that erythromycin and clindamycin resistance levels are higher than 10\% (De Mouy et al. 2001, Ferjani et al. 2006). According to the international scientific literature, it has been reported that, in Brazil, there

Financial support: CNPq, FAPERJ, CAPES, PRONEX, The Thrasher Research Fund

$\mathrm{ABAC}$ and LGS contributed equally to this work.

+ Corresponding author: beatrizcorrea@gmail.com

Received 7 April 2011

Accepted 25 November 2011 are strains that demonstrate sensitivity to penicillin, high resistance to tetracycline (above $75 \%$ ) and variable resistance to erythromycin and clindamycin (Oliveira et al. 2005, Palmeiro et al. 2010). The erm genes are associated with a resistance to macrolides, lincosamides and streptogramin B-type antibiotics $\left(\mathrm{MLS}_{\mathrm{B}}\right.$ phenotype). These genes may be expressed constitutively or their expression may be induced. The mef gene only confers resistance to macrolides ( $\mathrm{M}$ phenotype) and $\ln u \mathrm{~B}$ only confers resistance to lincosamides (De Mouy et al. 2001, Faccone et al. 2010).

Currently, 10 S. agalactiae serotypes have been described (Ia, Ib, II-IX) (Slotved et al. 2007). In the Western Hemisphere, the serotypes Ia, II, III and V are predominant (Tyrrell et al. 2000, Zaleznik et al. 2000, Gherardi et al. 2007, Martins et al. 2007, Mee-Marquet et al. 2009). Pulsed-field gel electrophoresis (PFGE) is the molecular typing method that has been used to evaluate the genetic diversity and clonal relatedness among $S$. agalactiae strains (Gherardi et al. 2007, Martins et al. 2007, Savoia et al. 2008). In Brazil, a few research groups are dedicated to studying the clonal diversity of $S$. agalactiae, using serotyping and antimicrobial susceptibility testing. These data provide epidemiological findings and may be useful in formulating efficient prevention and treatment strategies. The aim of this paper is to characterise S. agalactiae strains, which were mainly isolated from asymptomatic carriers, regarding their genetic diversity, capsular types, antimicrobial susceptibility profile and resistance to erythromycin and clindamycin determinants. 


\section{SUBJECTS, MATERIALS AND METHODS}

Bacterial strains - Sixty S. agalactiae strains collected from the vagina (asymptomatic pregnant woman, $\mathrm{n}=$ 51), urine (symptomatic adult, $\mathrm{n}=3$ ) and blood (symptomatic adult, $n=1$ ) of patients from Naval Hospital Marcílio Dias and from the oropharynx $(\mathrm{n}=5)$ of asymptomatic soldiers from Rio de Janeiro (RJ) between February-October 2008 were analysed. One isolate from each subject was included in this study. The identification of the isolates was confirmed using a Streptococcal Grouping Kit (Oxoid, Hampshire, UK). All of the strains were stored in Todd-Hewitt broth (Oxoid) with glycerol at $-80^{\circ} \mathrm{C}$.

Serotyping - The strains were serotyped by immunoprecipitation in agarose using antisera for type $\mathrm{Ia}, \mathrm{Ib}$ and II-VIII antigens, which were prepared in rabbits using recognised type strains and Lancefield hot-acid extracts from test and type strains (Lancefield \& Freimer 1966, Benchetrit et al. 1982).

Antimicrobial susceptibility testing - Susceptibility of the strains to penicillin, vancomycin, levofloxacin, clindamycin, chloramphenicol, erythromycin, rifampin and tetracycline (CECON, São Paulo, Brazil) was evaluated using the single-disk diffusion method and following the Clinical Laboratory Standards Institute guidelines (CLSI 2006). The agar-dilution assay was used following the CLSI guidelines (CLSI 2006) to determine the minimum inhibitory concentration (MIC) for the strains resistant to erythromycin and/or clindamycin. The erythromycinclindamycin double-disk test was used to determine the constitutive $\mathrm{MLS}_{\mathrm{B}}\left(\mathrm{cMLS}_{\mathrm{B}}\right)$ resistance, the inducible $\mathrm{MLS}_{\mathrm{B}}\left(\mathrm{iMLS}_{\mathrm{B}}\right)$ resistance and the $\mathrm{M}$ resistance phenotype, as previously described (Seppälä et al. 1993).

Polymerase chain reaction (PCR) for the detection of resistance to erythromycin and/or clindamycin genes The presence of the genes erm $\mathrm{A}, \operatorname{erm} \mathrm{B}, m e f \mathrm{~A} / \mathrm{E}$ and $\ln u \mathrm{~B}$ was detected in all erythromycin and/or clindamycin-resistant strains. DNA extraction was performed according to Sambrook et al. (1989). The reactions were performed in a GeneAmp PCR System 2400 (Applied Biosystems) using primers and cycles that have been previously described (Bozdogan et al. 1999, De Azavedo et al. 2001). PCR-amplified products were run on agarose gels and stained with ethidium bromide. The 100-bp lambda ladder kit (Invitrogen) was used as a DNA size marker.

$P F G E$ - PFGE was performed as previously described (Corrêa et al. 2009). The genomic DNA was digested with the SmaI restriction enzyme (Amersham Biosciences, UK) and electrophoresis was performed in a CHEF DR III system (Bio-Rad Laboratories, USA) using the following program: switch time 1-30 s during $23 \mathrm{~h}$ with a $120^{\circ}$ angle at a temperature of $11.3^{\circ} \mathrm{C}$ and a voltage gradient of $6 \mathrm{~V} / \mathrm{cm}$. The lambda ladder PFGE marker kit (New England Biolabs, USA) was used as a DNA size marker. The gels were stained with ethidium bromide and digitally photographed using a scanner Scorpion SCOR14SOM (DNR Bioimaging System) under ultraviolet light. The images were analysed by the Gel ComparII ${ }^{\circledR}$ software (Applied Maths, Belgium) and dendrograms of the genetic relationships among the strains were created.
The Dice coefficient (95\%) and a $1 \%$ position tolerance were used to analyse the similarities in the band patterns among the electrophoretic profiles. The unweighted pair group method using the arithmetic average was used to cluster electrophoretic profiles into polymorphism patterns, also referred to as clusters. Briefly, electrophoretic profiles that showed $100 \%$ similarity were considered indistinguishable and profiles with similarities $>80 \%$ were considered clonally related (Singh et al. 2006).

\section{RESULTS}

The following strains were distinguished using serotype classification: $20(33.2 \%)$ serotype Ia, one (1.7\%) serotype Ib, nine (15\%) serotype II, three (5\%) serotype III, one $(1.7 \%)$ serotype IV, nine $(15 \%)$ serotype V and one $(1.7 \%)$ serotype VIII strains. Serotypes VI and VII were not found and $26.7 \%$ (16) of the strains were nontypable using this method (Figure).

All of the isolates were susceptible to penicillin, vancomycin and levofloxacin. Resistance to clindamycin, chloramphenicol, erythromycin, rifampin and tetracycline was detected in $10(16.7 \%)$, three (5\%), eight (13.2\%) and $49(81.7 \%)$ strains, respectively (Figure). Among the eight erythromycin resistant strains, seven were also resistant to clindamycin and had a $\mathrm{cMLS}_{\mathrm{B}}$ phenotype. The strain resistant to only erythromycin contained the $m e f \mathrm{~A} / \mathrm{E}$ gene had an M phenotype and a MIC of $2 \mathrm{mg} / \mathrm{L}$. Among the strains resistant to both antibiotics, erm $\mathrm{A}$ was detected in four $(50 \%)$ strains, ermB was detected in two $(25 \%)$ and only one of the ermA-positive strains also carried ermB. Two of these strains did not contain resistance genes and had a MIC of $1 \mathrm{mg} / \mathrm{L}$ to erythromycin and MICs of $8 \mathrm{mg} / \mathrm{L}$ and $16 \mathrm{mg} / \mathrm{L}$ to clindamycin. Three strains were resistant to only clindamycin (L phenotype) with MICs between 8-16 mg/L. The resistance genetic determinant, however, was not detected.

Fifty-six different PFGE electrophoretic profiles were identified among the 60 strains and 22 of these profiles were grouped into 11 polymorphism patterns. The predominant pattern, designated pattern 1 , included four serotype Ia strains and one serotype V strain. All of these strains were vaginal isolates and were resistant to only tetracycline. Pattern 2 included two serotype Ia strains isolated from the vagina and one nontypable strain isolated from the oropharynx and all of these strains were resistant to tetracycline. Each of the other nine patterns contained only two strains. The isolates from the infectious sites (urine or blood) displayed unique electrophoretic profiles (Figure).

\section{DISCUSSION}

Susceptibility to penicillin, vancomycin and levofloxacin in addition to a high level of resistance to tetracycline $(81.7 \%)$ was observed in this study. These data are consistent with previously published data on S. agalactiae strains from human origins in other countries (De Mouy et al. 2001, Ferjani et al. 2006, Gherardi et al. 2007, Savoia et al. 2008), including Brazil (Duarte et al. 2005, Oliveira et al. 2005, Palmeiro et al. 2010). Although strains resistant to penicillin and levofloxacin have been described, they remain rare (Kimura et al. 2008, Llaneza et al. 2009, Nakamura et al. 2011). 


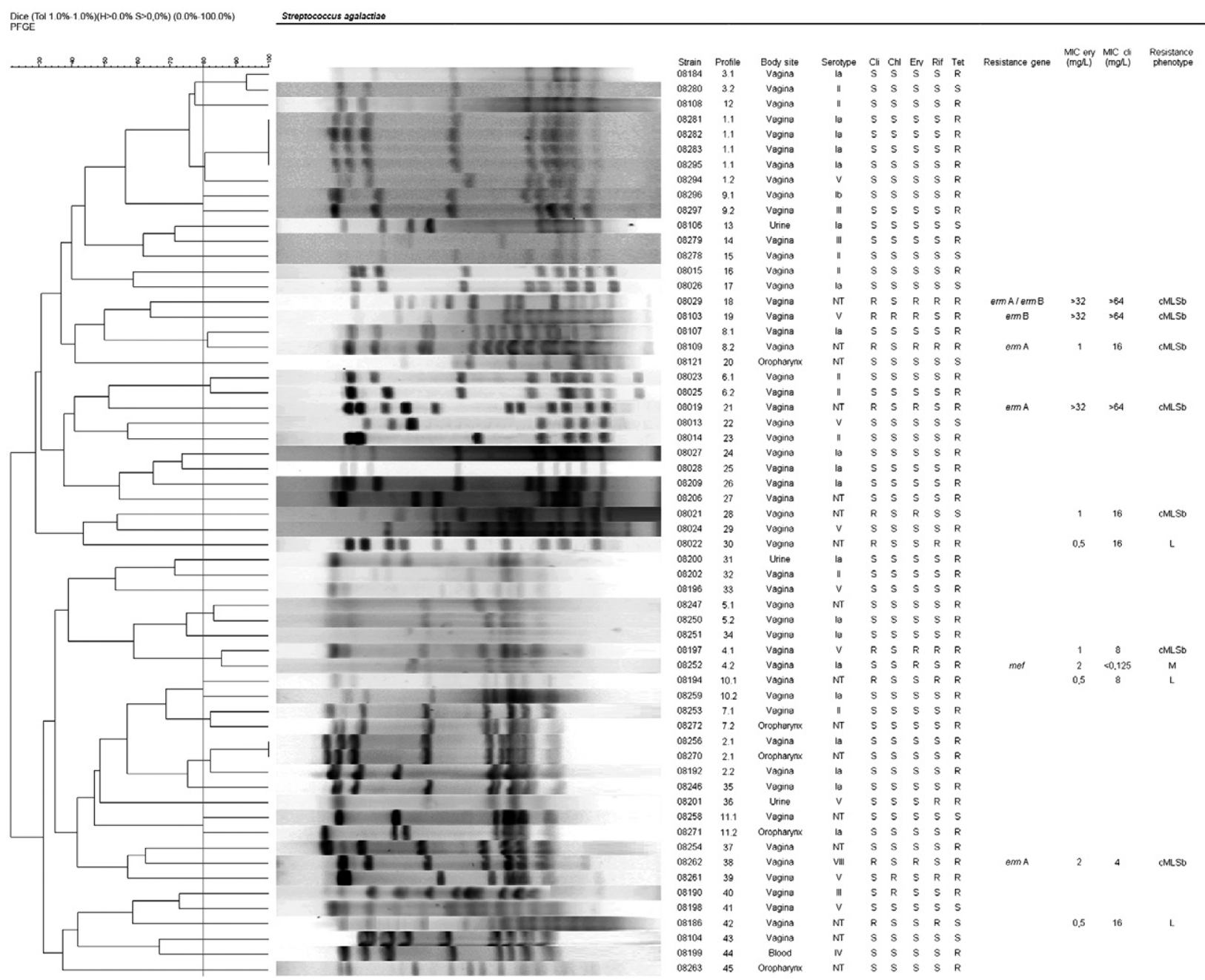

Genetic diversity and phenotypic characterization of S. agalactiae isolates. The vertical line shows the similarity cut-off. Pulsed-field gel electrophoresis (PFGE) profiles obtained, strain numbers, attributed PFGE identification, body site sample, serotypes, antimicrobial tests (Chl: chloramphenicol; Cli: clindamycin; Ery: erythromycin; Rif: rifampin; Tet: tetracycline), resistance gene, minimum inhibitory concentration (MIC) and resistance phenotype. $\mathrm{cMLS}_{\mathrm{B}}$ : constitutive macrolides, lincosamides and streptogramins B-type resistance; L: lincosamides resistance; M: macrolides resistance; NT: nontypable; R: resistant; S: sensitive.

Resistance to clindamycin, erythromycin, chloramphenicol and rifampin was detected. Levels of resistance to macrolides and lincosamides lower than $9 \%$ have been previously described in Brazil (Duarte et al. 2005, Oliveira et al. 2005, Palmeiro et al. 2010). A recent study from RJ reported erythromycin and clindamycin resistance in $14 \%$ and $5 \%$ of the strains studied, respectively (Nakamura et al. 2011). Our results indicate that there is an increase in erythromycin resistance in RJ compared to other Brazilian studies. This increase, however, is not as high as the international data (Ferjani et al. 2006, Gygax et al. 2007). In the present study, greater than $85 \%$ of the erythromycin resistant strains had the $\mathrm{cMLS}_{\mathrm{B}}$ phenotype. This finding suggests that this phenotype may be used to identify not only erythromycin resistant strains, but also clindamycin and streptogramins B resistant strains. Supporting this claim, Nakamura et al. (2011) described an inducible or constitutive $\mathrm{MLS}_{\mathrm{B}}$ phenotype in more than
$75 \%$ of strains. All of the clindamycin and/or erythromycin resistant strains identified were isolated from pregnant women and the resistance of $14 \%$ (7 strains) of these strains to both antibiotics makes their use impractical.

The genes ermA, erm B and mefA/E were detected in only seven of the eight erythromycin and clindamycin resistant isolates. Therefore, it is possible that another gene is responsible for the phenotypic resistance observed in the remaining isolate. Betriu et al. (2003) reported that the most prevalent gene detected in the strains studied was erm $\mathrm{B}(70 \%)$ and that $e r m \mathrm{~A}$ and $m e f \mathrm{~A} / \mathrm{E}$ were detected in $48 \%$ and $6 \%$ of strains, respectively. Other groups have reported similar data (Pinheiro et al. 2009). Consistent with this previous data, a correlation between resistance genes and the macrolide resistance phenotype was also observed in this study (Duarte et al. 2005, Pinheiro et al. 2009). In this study, we did not detect any relationship between the MICs and the erythromycin phenotype 
or genetic resistance determinant, which is inconsistent with previous observations (Mollerach et al. 2007, Nakamura et al. 2011). There was no relationship between the PFGE profiles of resistant erythromycin and/or resistant clindamycin strains.

Serotypes Ia, II, III and V represent approximately $80-90 \%$ of the isolates from clinical cases in the USA, Europe and Australia, whereas serotypes IV, VI, VII, VIII and IX are rare (Zeng et al. 2006, Slotved et al. 2007, Zhao et al. 2008) In our study, we observed the serotypes Ia, II, III and V in $68.2 \%$ of all the tested strains. This finding is consistent with the previously reported data. Approximately $25 \%$ of our strains were nontypable. In previous studies, however, only $3-15 \%$ of the tested strains were described as nontypable (Tyrrell et al. 2000, Zaleznik et al. 2000). The use of molecular techniques may explain this discrepancy between the typing of our isolates and the isolates in previous studies. Serotypes Ia, II, III and V were also the most prevalent serotypes observed among the pregnant women in this study. In this study, more than $70 \%$ of these strains exhibited serotypes Ia, II, III or V. Based on this finding and previously published data, we suggest that the development of a vaccine for the most common serotypes found around the world (Ia, II, III and V) could be an effective treatment for Brazilian pregnant women. This type of vaccine could minimise the use of prophylactic antimicrobials during labour, which is used to prevent the early onset of the disease. It may also influence the occurrence of the late-onset disease, which is not affected by prophylaxis with antibiotics.

In the present study, we identified a strain of serotype VIII, which was isolated from a pregnant woman. This strain was resistant to clindamycin, erythromycin and tetracycline and carried the ermA gene. This isolate is the first serotype VIII strain reported in Brazil. We could not decipher a relationship between the serotypes and the collection sites or a relationship between the serotypes and PFGE profiles. Interestingly, only one erythromycin resistant strain was identified in the serotype Ia group, even though this serotype is the most prevalent. No relationship was found between the serological types and the PFGE profiles.

In this study, we observed a high genetic heterogeneity among the strains. Among the 60 tested strains, 56 electrophoretic profiles were identified and only 22 of these profiles could be clustered into polymorphism patterns. Previous studies have described a lower genetic heterogeneity among the $S$. agalactiae isolates from Brazil and other countries (Gherardi et al. 2007, Martins et al. 2007, Savoia et al. 2008, Palmeiro et al. 2010). Even though an epidemiological link between the strains isolated from the oropharynx could be made, such as soldiers working in the same quarters and easily transmitting samples orally, there was no genetic relationship observed between the strains of oropharynx analysed. Furthermore, even though an epidemiological link cannot be made between strains isolated from the vagina of pregnant women, a genetic relationship was detected between these strains. No relationship was found between serological types and PFGE profiles.
An investigation of the genetic diversity in $S$. agalactiae isolates enables us to accurately characterise the bacterial epidemiology. In this study, $85 \%$ of the isolates were collected from pregnant women. Therefore, our data on genetic diversity, serological typing and antimicrobial susceptibility profiling are extremely valuable considering that the early and the late-onset diseases often originate from vaginal maternal microbiota. Our data may be useful in developing preventative measures against these infections, especially the late-onset disease, which is not prevented by antimicrobial prophylaxis.

\section{REFERENCES}

Benchetrit LC, Fracalanzza SEL, Peregrino H, Camelo AA, Sanches LALR 1982. Carriage of Streptococcus agalactiae in women and neonates and distribution of serological types: a study in Brazil. J Clin Microbiol 15: 787-790.

Betriu C, Culebras E, Gómez M, Rodríguez-Avial I, Sánchez BA, Agreda MC, Picazo JJ 2003. Erythromycin and clindamycin resistance and telithromycin susceptibility in Streptococcus agalactiae. Antimicrob Agents Chemother 47: 1112-1114.

Bozdogan B, Berrezouga L, Kuo MS, Yurek DA, Farley KA, Stockman BJ, Leclercq LA 1999. A new resistance gene, $\operatorname{lin} \mathrm{B}$, conferring resistance to lincosamides by nucleotidylation in Enterococcus faecium HM1025. Antimicrob Agents Chemother 43: 925-929.

CDC - Centers for Disease Control and Prevention 2002. Prevention of perinatal group B streptococcal diseases: revised guidelines from CDC. MMWR CDC Surveill Summ (Atlanta GA) 51: 11.

CLSI - Clinical and Laboratory Standards Institute 2006. Performance standards for antimicrobial susceptibility testing: 16th informational supplement, M100-S16 26, CLSI, Wayne, p. 138-140.

Corrêa ABA, Oliveira ICM, Pinto T de CA, Mattos MC, Benchetrit LC 2009. Pulsed-field gel electrophoresis, virulence determinants and antimicrobial susceptibility profiles of type Ia group B streptococci isolated from humans in Brazil. Mem Inst Oswaldo Cruz 104: 599-603.

De Azavedo JCS, McGavin M, Duncan C, Low DE, McGeer A 2001. Prevalence and mechanisms of macrolide resistance in invasive and noninvasive group B streptococcus isolated from Ontario, Canada. Antimicrob Agents Chemother 45: 3504-3508.

De Mouy D, Cavallo JD, Leclercq R, Fabre R, AFIRCORP-BIO Network 2001. Antibiotic susceptibility and mechanisms of erythromycin resistance in clinical isolates of Streptococcus agalactiae: French multicenter study. Antimicrob Agents Chemother 45: 2400-2402.

Duarte RS, Bellei BC, Miranda OP, Brito MAVP, Teixeira LM 2005. Distribution of antimicrobial resistance and virulence-related genes among Brazilian group B streptococci recovered from bovine and human sources. Antimicrob Agents Chemother 49: 97-103.

Faccone D, Lalonardi F, Abel S, Machain M, Errecalde L, Littvik A, Kauffman S, Galas M, WHONET-Argentina Group, Corso A 2010. Multiple-clones of Streptococcus agalactiae harbouring lnuB gene. J Infect Dev Ctries 4: 580-582.

Ferjani A, Ben Abdallah H, Ben Saida N, Gozzi C, Boukadida J 2006. Vaginal colonization of the Streptococcus agalactiae in pregnant woman in Tunisia: risk factors and susceptibility of isolates to antibiotics. Bull Soc Pathol Exot 99: 99-102.

Gherardi G, Imperi M, Baldassarri L, Pataracchia M, Alfarone G, Recchia S, Orefici G, Dicuonzo G, Creti R 2007. Molecular epidemiology and distribution of serotypes, surface proteins and 
antibiotic resistance among group B streptococci in Italy. $J$ Clin Microbiol 45: 2909-2916.

Gygax SE, Schuyler JA, Kimmel LE, Trama JP, Mordechai E, Adelson ME 2007. Detection of erythromycin and clindamycin resistance genes in group B streptococcal clinical isolates and cervicovaginal-rectal swabs. Microb Drug Resist 13: 119-123.

Kimura K, Suzuki S, Wachino J, Kurokawa H, Yamane K, Shibata N, Nagano N, Kato H, Shibayama K, Arakawa Y 2008. First molecular characterization of group B streptococci with reduced penicillin susceptibility. Antimicrob Agents Chemother 52: 2890-2897.

Lancefield RC, Freimer EH 1966. Type-specific polysaccharide antigens of group B streptococci. J Hyg (Lond) 64: 191-203.

Llaneza E, Seral C, Castillo FJ, Durán E, Rubio-Calvo C, GómezLus R 2009. Characterization of clinical blood isolates of Streptococcus agalactiae with reduced susceptibility to levofloxacin. J Chemother 21: 463-464.

Martins ER, Pessanha MA, Ramirez M, Melo-Cristino J, Portuguese Group for the Study of Streptococcal Infections 2007. Analysis of group B streptococcal isolates from infants and pregnant women in Portugal revealing two lineages with enhanced invasiveness. J Clin Microbiol 45: 3224-3229.

Mee-Marquet N, Jouannet C, Domelier AS, Arnault L, Lartigue MF, Quentin R 2009. Genetic diversity of Streptococcus agalactiae strains and density of vaginal carriage. Med Microbiol 58: 169-173.

Mollerach A, Méndez E, Massa R, Di Conza J 2007. Streptococcus agalactiae isolated in Santa Fe, Argentina: antibiotic susceptibility and erythromycin-clindamycin resistance mechanisms. Enferm Infecc Microbiol Clin 25: 67-68.

Nakamura PAM, Schuab RBB, Neves FPG, Pereira CFA, de Paula GR, Barros RR 2011. Antimicrobial resistance profiles and genetic characterisation of macrolide resistant isolates of Streptococcus agalactiae. Mem Inst Oswaldo Cruz 106: 119-122.

Oliveira ICM, Mattos MC de, Areal MFT, Ferreira-Carvalho BT, Figueiredo AMS, Benchetrit LC 2005. Pulsed-field gel electrophoresis of human group B streptococci isolated in Brazil. J Chemother 17: 258-263.

Palmeiro JK, Dalla-Costa LM, Fracalanzza SE, Botelho AC, Silva Nogueira K da, Scheffer MC, Almeida Torres RS de, Carvalho NS de, Cogo LL, Madeira HM 2010. Phenotypic and genotypic characterization of group B streptococcal isolates in southern Brazil. J Clin Microbiol 48: 4397-4403.
Pinheiro S, Radhouani H, Coelho C, Gonçalves A, Carvalho E, Carvalho JA, Ruiz-Larrea F, Torres C, Igrejas G, Poeta P 2009. Prevalence and mechanisms of erythromycin resistance in Streptococcus agalactiae from healthy pregnant women. Microb Drug Resist 15: 121-124.

Sambrook J, Fritsh EF, Maniatis T 1989. Molecular cloning: a laboratory manual, Cold Spring Harbor Laboratory Press, New York, $1659 \mathrm{pp}$.

Savoia D, Gottimer C, Crocilla C, Zucca M 2008. Streptococcus agalactiae in pregnant women: phenotypic and genotypic characters. J Infect 56: 120-125.

Schrag SJ, Zywicki S, Farley MM, Reingold AL, Harrison LH, Lefkowitz LB, Hadler JL, Danila R, Cieslak PR, Schuchat A 2000. Group B streptococcal disease in the era of intrapartum antibiotic prophylaxis. $N$ Engl J Med 342: 15-20.

Seppälä H, Nissinen A, Yo Q, Huovinen P 1993. Three different phenotypes of erythromycin-resistant Streptococcus pyogenes in Finland. J Antimicrob Chemother 32: 885-891.

Singh A, Goering RV, Simjee S, Foley SL, Zervos MJ 2006. Application of molecular techniques to the study of hospital infection. Clin Microbiol Rev 19: 512-530.

Slotved HC, Kong F, Lambertsen L, Sauer S, Gilbert GL 2007. Serotype IX, a proposed new Streptococcus agalactiae serotype. J Clin Microbiol 45: 2929-2936.

Tyrrell GJ, Senzilet LD, Spika JS, Kertesz DA, Alagaratnam M, Lovgren M, Talbot JA 2000. Invasive disease due to group B streptococcal infection in adults: results from a Canadian, population-based, active laboratory surveillance study - 1996. Sentinel Health Unit Surveillance System Site Coordinators. J Infect Dis 182: 168-173.

Zaleznik DF, Rench MA, Hillier S, Krohn MA, Platt R, Lee ML, Flores AE, Ferrieri P, Baker CJ 2000. Invasive disease due group $\mathrm{B}$ streptococcus in pregnant women and neonates from diverse population groups. Clin Infect Dis 30: 276-281.

Zeng X, Kong F, Wang H, Darbar A, Gilbert GL 2006. Simultaneous detection of nine antibiotic resistance-related genes in Streptococcus agalactiae using multiplex PCR and reverse line blot hybridization assay. Antimicrob Agents Chemother 50: 204-209.

Zhao Z, Kong F, Zeng X, Gidding HF, Morgan J, Gilbert GL 2008. Distribution of genotypes and antibiotic resistance genes among invasive Streptococcus agalactiae (group B streptococcus) isolates from Australasian patients belonging to different age groups. Clin Microbiol Infect 14: 260-267. 